\title{
Effect of Laser Patterning on Properties of Crystalline Si Photovoltaic Cells and Substrates
}

\author{
Antanas VINČIŪNAS, Simonas INDRIŠIŪNAS, Bogdan VOISIAT, Gediminas RAČIUKAITIS, Irena ŠIMKIENĖ, \\ Rasa SUZANOVIČIENĖ, Alfonsas RĖZA and Regina MAŽEIKIENĖ \\ ${ }^{* 1}$ Center for Physical Science and Technology, Savanoriu Ave. 231, LT-02300 Vilnius, Lithuania \\ E-mail: graciukaitis@ar.fi.lt
}

\begin{abstract}
Silicon used as active medium in solar cell production reflects a considerable part of solar light due to its high refraction index, especially when the light incidents not perpendicularly to its surface. Texturing of the surface can increase the solar energy coupling within an active medium. We present results of laser texturing of poly-Si solar cells surface by direct laser writing and novel Laser Beam Interference Ablation techniques. Solar cells with laser-modified surface were characterized by optical and Raman spectroscopy as well as photo-electrically. After laser texturing of polycrystalline silicon solar cells, reflection from their surface was reduced by up to $14 \%$. Structural defects induced by laser irradiation and ablation decreased the lifetime of photo-generated charge carriers and they could not reach the p-n junction. Laser texturing of silicon substrate can be done using direct ablation by interfering laser beams. A reduction in the structure period was demonstrated by up to 3 times by sub-period shift of the workpiece between exposures.

DOI: $10.2961 / \mathrm{jlmn} .2013 .03 .0010$
\end{abstract}

Keywords: Silicon solar cells, laser texturing, laser beam interference, light trapping, PV efficiency

\section{Introduction}

Light harvesting is becoming an important way for further progress to highly efficient solar-to-electricity convertors. The photon trapping structures on substrate, cell surface and inside active materials are being investigated intensively $[1,2]$. They are based on interference, diffraction or resonant plasmonic effects. The efficiency of solar cells can be increased by reducing the reflection of solar light from the illuminated surface. Surface texturing is an efficient method to enhance the light absorption by multiple internal reflections. As a result, the light is absorbed in a close proximity to the p-n-junction.

There are two ways to modify the solar cell surface for trapping of the incident light. One way is the creation of randomly distributed pyramids by direct chemical etching in alkali solutions [3]. As the etching rate differs in various crystallographic directions, a pyramidal structure can be formed in mono-crystalline silicon solar cells. Unfortunately, this technique cannot work effectively on polycrystalline silicon wafers. On the other hand, alkali etching can cause undesirable fractures on the surface of the polycrystalline silicon solar cell [4]. Therefore, for texturing of polycrystalline silicon solar cells, the etching in acid solutions based on $\mathrm{HNO}_{3}: \mathrm{HF}$ [5], mechanical etching using diamond edge [6], reactive ion etching [7] and plasma etching [8] have been proposed. All of them have limitations in size and aspect ratio of texturing.

The other novel methods for texturing polycrystalline silicon (poly-Si) solar cells use laser ablation [9]. Lasers can produce surface structures which are able to trap photons [10]. PV efficiency of c-Si solar cells was increased by $2 \%$ when nano-hole matrixes were formed by a laser in anti-reflective $\mathrm{Si}_{3} \mathrm{~N}_{4}$ coating [11]. The effective area of organic solar cells was increased by texturing polymeric substrate using laser ablation with beam interference [12].

We applied different laser texturing techniques to modify the surface of polycrystalline silicon solar cells with the purpose to increase absorption, angle acceptance and photovoltaic efficiency of the cells. Direct laser writing and Laser Beam Interference Ablation techniques were used for laser patterning. We discuss the influence of the laser process parameters on optical properties of the Si polycrystalline solar cells.

\section{Experimental setups and procedures}

Two laser techniques were applied for surface modification of polycrystalline silicon solar cells. Direct Laser Writing (DLW) is based on the use of a tightly focused laser bean to ablate material locally (Fig. 1). Scanning with a galvoscanner was used to structure the whole surface of the sample.

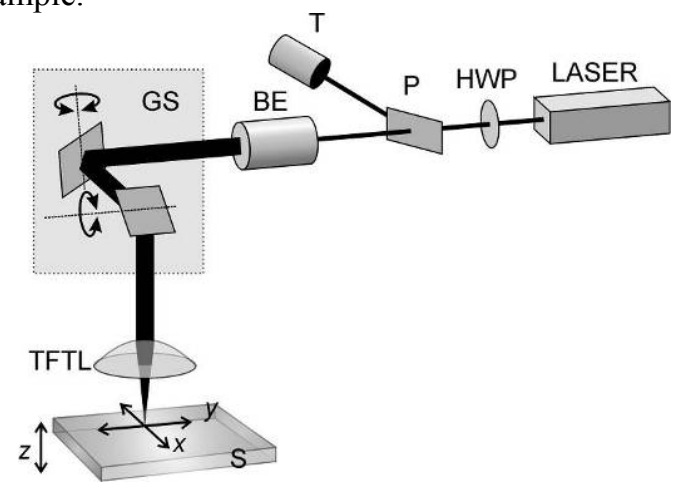

Fig. 1 Setup for laser texturing using Direct Laser Writing. 
The second method was based on the formation of a periodical intensity distribution on a sample surface by using laser beam interference. This method is called Laser Beam Interference Ablation (LBIA). The laser beam was split into 3, 4 or 6 beams and combined back by an optical setup made of two lenses (Fig. 2) $[13,14]$ or a special setup with symmetrically arranged mirrors [15]. Diverging beams after passing a diffractive optical element were collected back together by the mirrors fixed permanently on a precisely machined metallic holder. The convergence angle of the beams was fixed by the holder design. With the mirror setup, a period of structuring as small as $600 \mathrm{~nm}$ was achieved using a $532 \mathrm{~nm}$ wavelength.

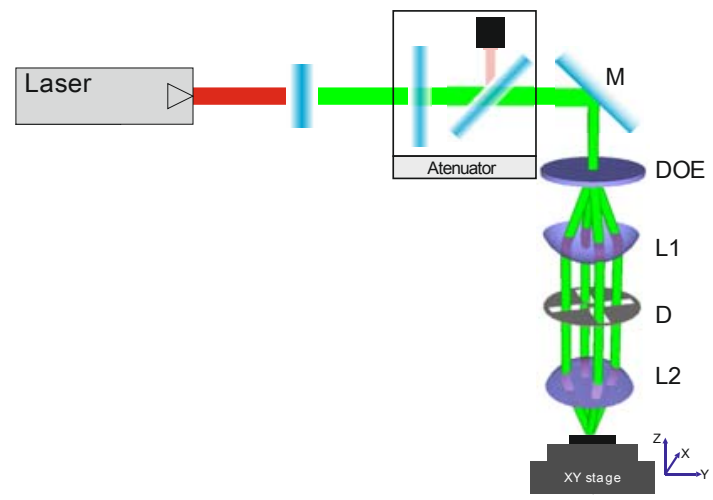

Fig. 2 Setup for Laser Beam Interference Ablation with two lenses.

Table 1 Parameter of laser techniques used in texturing experiments.

\begin{tabular}{lllll}
\hline Laser parameters & DLW & \multicolumn{3}{l}{ ns-LBIA ps-LBIA fs-LBIA } \\
\hline Wavelength, nm & 532 & 532 & 532 & 515 \\
Pulse duration & $10 \mathrm{~ns}$ & $25 \mathrm{~ns}$ & $60 \mathrm{ps}$ & $200 \mathrm{fs}$ \\
Max pulse energy, mJ & 0.5 & 3.5 & 0.4 & 2.4 \\
Max rep. rate, $\mathrm{kHz}$ & 100 & 0.5 & 4 & 1 \\
Spot size $\left(1 / \mathrm{e}^{2}\right), \mu \mathrm{m}$ & 120 & 500 & 500 & 1300 \\
\hline
\end{tabular}

When analyzing data from our small solar farm on the roof of our laboratory building with fixed mono- and polysilicon solar panels of the same size we were surprised to see that poly-Si modules even with an efficiency lower by $0.6 \%$ generate $1-2 \%$ more photo-electricity than mono-Si of the same module size in Lithuania where clear sky and direct sun illumination is not dominating. Rising \& falling trajectory of the sun corresponds to electrical power generated by the PV modules, and polycrystalline material possesses better angle acceptance for illumination. Therefore, poly-Si cells have been selected as research object in order to improve absorption and PV characteristics of the cells.

The experiments were performed on the commercial polycrystalline silicon solar cells with an area of $(15 \times 15$ $\mathrm{cm}^{2}$ ) and an average PV efficiency of about $14 \%$. At the initial stage of the experiments, wafers were laser-cut into $1 \times 2 \mathrm{~cm}^{2}$ samples.

When proper regimes of structuring were selected, the whole surface of a cell was structured as follows (Fig. 3):

口 DLW: 12 lines scanned between contact grid, distance between scanning lines was $100 \mu \mathrm{m}$.
- LBIA: 3 lines scanned between contact grid, distance between scanning lines was $575 \mu \mathrm{m}$.
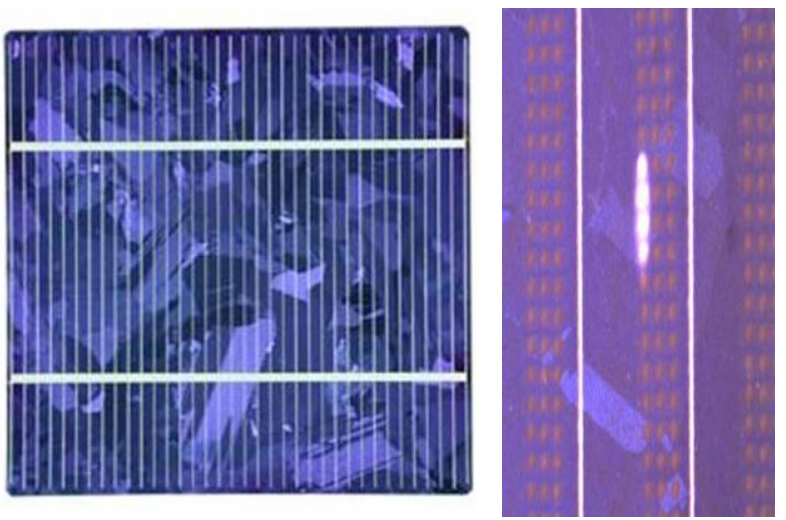

Fig. 3 Poly-Si solar cells used in the experiments. Size 5" x 5" PV efficiency $\sim 14 \%$, with $\mathrm{SiN}_{\mathrm{x}}$ layer on top. Right: Segment of the cell with laser patterning spots between metal grids. Illumination spot in reflection measurement is shown in white.

Characterization of the laser modified surfaces was performed using Raman spectroscopy as well as absorption and reflection measurements. Raman spectra were investigated using an inVia Raman spectrometer-microscope (Renishaw, UK) using gratings with 1800 and 2400 lines/mm and a CCD detector cooled by liquid nitrogen. Excitation was performed by a He-Ne laser at $633 \mathrm{~nm}$. Excitation power at the sample surface was $1 \mathrm{~mW}$. A 50x objective and an accumulation time of $100 \mathrm{~s}$ were used during Raman spectra registration. Parameters of the lines were evaluated using GRAMS spectral analysis and GaussLorentz approximation.

As silicon has strong absorption in the spectral range of $250-900 \mathrm{~nm}$, there is no direct possibility to measure optical transmission. Therefore, the reflection was measured by an ellipsiometric method using polarized light. Optical investigations were performed using VASE (RG-2) photometric spectrometer (J.A. Woollam Co, USA) in the spectral range of $200 \mathrm{~nm}$ to $1700 \mathrm{~nm}$. The experimental results were analyzed in approximation of pseudo-dielectric function for isotropic media. If an incident angle is equal to $\Theta$, the complex reflection coefficient $\rho$ can be expressed as:

$$
\rho=\left|\frac{r_{p}}{r_{s}}\right| \exp (i \Delta)=\tan \Psi \exp (i \Delta),
$$

here $\Psi$ and $\Delta$ are the ellipsometric parameters.

Measurements were performed at the incident angle $\Theta$ $=75^{\circ}$. Ellipsometric parameters were measured in the ranges of $\Psi=45.0 \pm 0.05^{\circ}$ and $\Delta=0 \div 180 \pm 0.1^{\circ}$. Using experimental data of $\Psi$ and $\Delta$, the real part $\left(\varepsilon_{1}=n^{2}-k^{2}\right)$ and imaginary part $\left(\varepsilon_{2}=2 n k\right)$ of the refraction index were calculated and used to find the reflection and absorption coefficients:

$$
\begin{aligned}
& R=\frac{(n-1)^{2}+k^{2}}{(n+1)^{2}+k^{2}} \\
& K=\frac{2 \pi \varepsilon_{2}}{\lambda n}
\end{aligned}
$$

with $\lambda$ being the wavelength.

Diffuse reflectance was studied by means of the Shimadzu UV-VIS-NIR Spectrophotometer UV-3600 coupled with the MRC-3100 unit. Measurements were performed by mounting a sample holder onto the integrating sphere. 
The measurable range of wavelengths is between $240 \mathrm{~nm}$ and $2600 \mathrm{~nm}$ covering the UV, visible and the near infrared regions. In the integrating sphere, one beam strikes the sample normally to the surface while the other beam strikes aslant. From the diffuse reflection coefficient the light absorbance was calculated using the Kubelka-Munk theory [16].

\section{Patterning of poly-Si solar cells using focused laser beam}

Direct laser writing with a galvoscanner is an easy way to texture materials by a focused laser beam when the period of a structure is much larger than the wavelength. Texturing of the cell surface was performed by scanning over its surface and irradiating every $250 \mu \mathrm{m}$ (period). The laser pulse energy and the number of laser pulses per spot were varied during the texturing experiments. When a high number of laser pulses was applied, the protective layer of $\mathrm{SiN}_{\mathrm{x}}$ was ablated and a microstructure was self-organized within the spot area as shown in the optical and scanning electron microscope (SEM) images in Fig. 4.
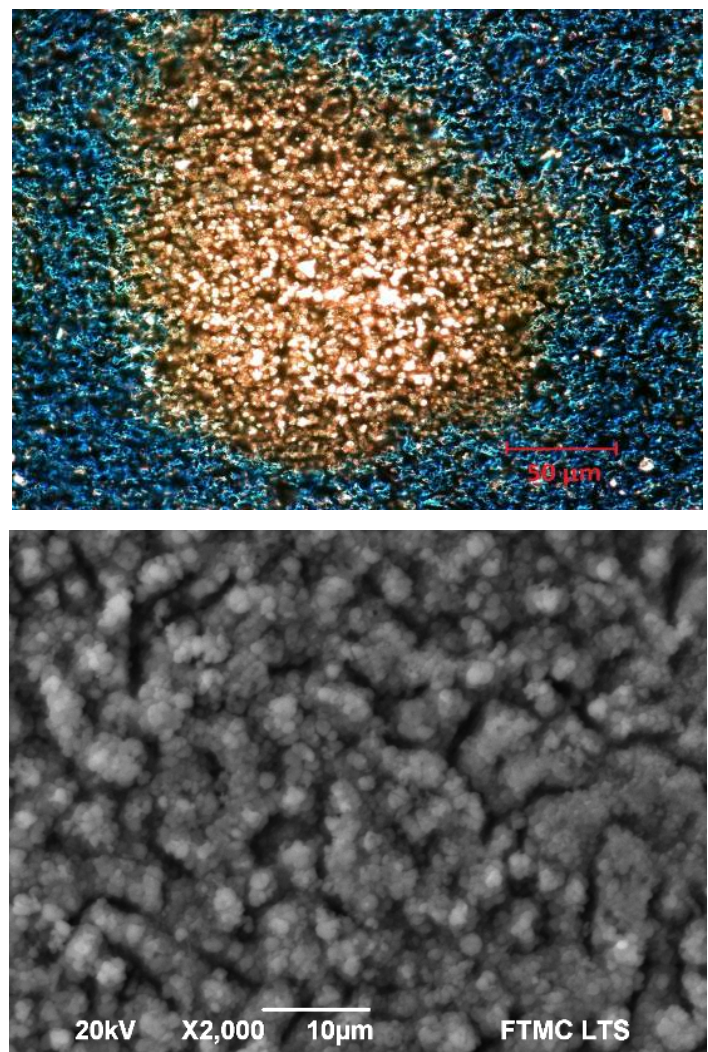

Fig. 4 Optical and SEM images of poly-Si solar cell surface irradiated by a single exposure of the focused laser beam from nanosecond (10 ns) laser. Pulse energy $0.5 \mathrm{~mJ} ; 15000$ pulses.

The reflection and absorption properties of lasermodified surfaces were evaluated by ellipsometric methods, and the alteration in the chemical composition was controlled by electron dispersion spectroscopy (EDS). Raman scattering measurements were performed on some samples to investigate the crystalline structure of the silicon surface.
Fig. 5 presents an example of the ellipsometric measurement results when real and imaginary parts of the dielectric function were evaluated from experimental data.

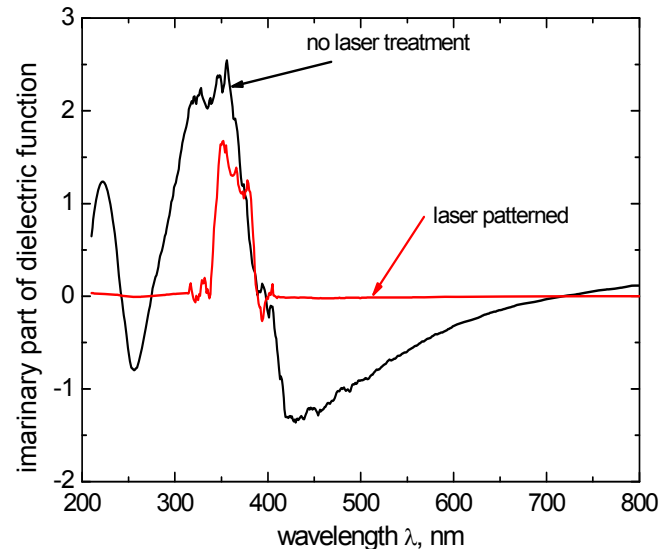

Fig. 5 Spectral distribution of the imaginary part of dielectric function. Samples: untreated and treated with ns-laser (10 ns, 3 W@10kHz, 15000 pulses).

Fig. 6 presents the absorption and reflection spectra of laser-modified solar cells. After laser irradiation, the surface reflection in the "blue" spectral part $(<480 \mathrm{~nm})$ was reduced from $26 \%$ to $12 \%$, but it increased in the red part of visible spectrum. Laser texturing of this kind had the strongest influence on the cell absorption of around $600 \mathrm{~nm}$.
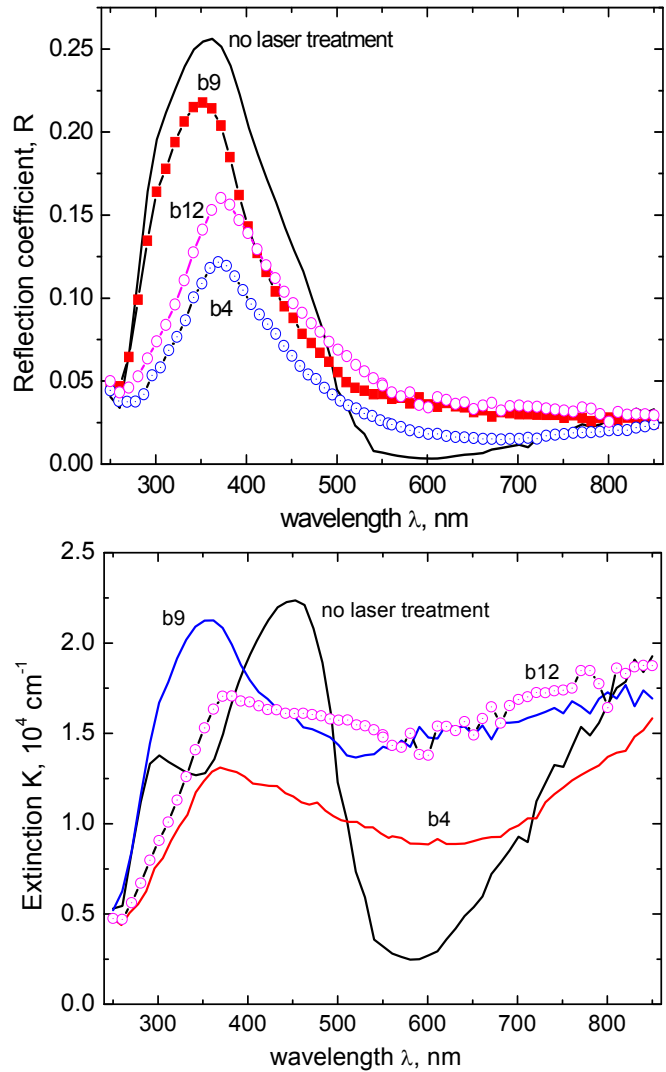

Fig. 6 Absorption (extinction) and reflection spectra of laser by DLW textured poly-Si solar cells, evaluated from ellipsometric measurements in the dielectric function approximation. Laser texturing regimes: b4: $0.2 \mathrm{~mJ}$ 30000 pulses, spot $\varnothing 100 \mu \mathrm{m}$; b9: $0.4 \mathrm{~mJ} ; 10000$ pulses, spot $\varnothing 180 \mu \mathrm{m} ; \mathrm{b} 12: 0.5 \mathrm{~mJ} ; 30000$ pulses, spot $\varnothing 190 \mu \mathrm{m}$. The texuring period was $250 \mu \mathrm{m}$. 
The reflection from the poly-Si solar cell surface was reduced in the short-wavelength range, and a small increase was observed in thelong-wavelength part. Most of those modification was related with damage of anti-reflecting passivation layer of $\operatorname{SiN}_{\mathrm{x}}$.

\section{Texturing of poly-Si solar cells using ns-LBIA}

A surface structure with desired period can be easily made using a few interfering laser beams. We performed experiments with lasers of different pulse duration in texturing the surface of poly-Si solar cells.

This section presents results achieved using laser beam interference and nanosecond- pulsed lasers. As the laser beam is not focused in LBIA technique, depending on the pulse energy available from the laser, plenty of pulses were applied to the same location on a sample to achieve a visible modification of the cell surface. Those visible modifications were related to self-organization of material under laser irradiation independent of the interference period as shown in Fig. 7.

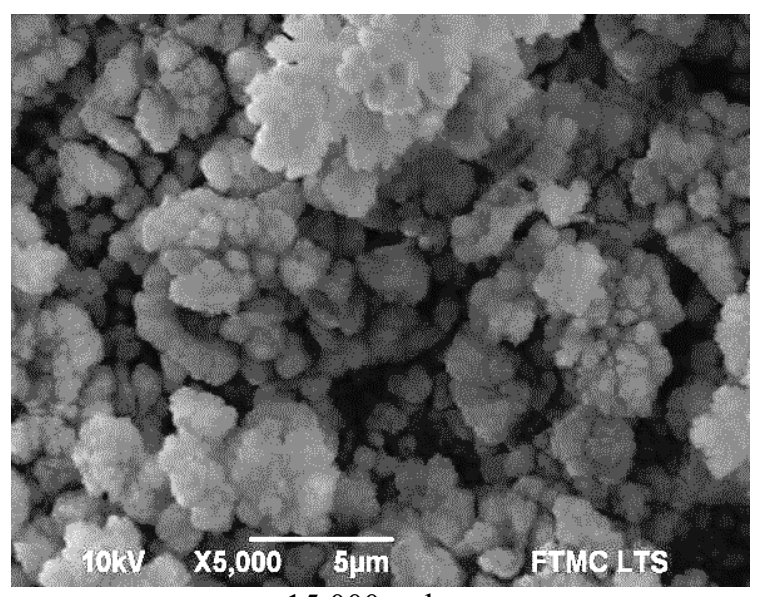

15000 pulses

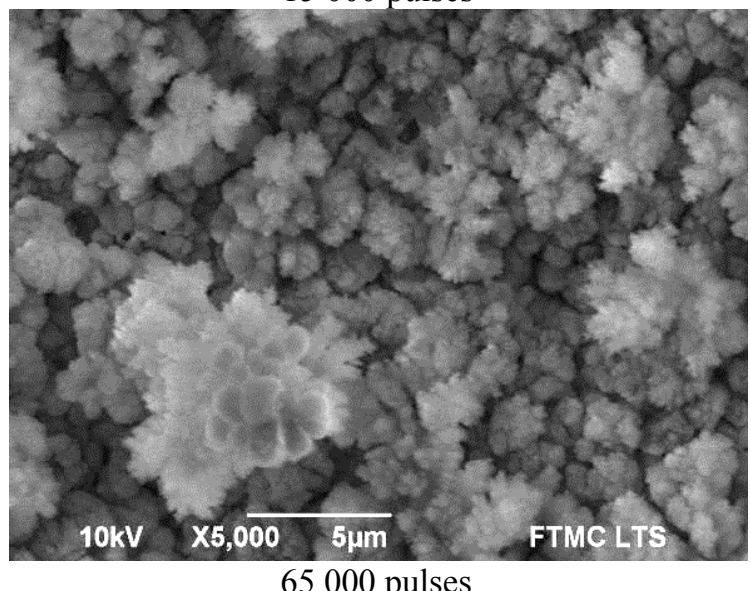

65000 pulses

Fig. 7 SEM images of poly-Si solar cell surface irradiated by 3 interfering laser beams. Period was $600 \mathrm{~nm}$. Pulse energy was $0.35 \mathrm{~mJ}$.

The influence of laser patterning parameters on the optical properties of polycrystalline silicon photovoltaic cells was also investigated by optical and Raman spectroscopy. Even with a low number of laser pulses applied, when no visible modification of the surface appeared, alterations in the diffuse reflection spectra were observed (Fig. 8).

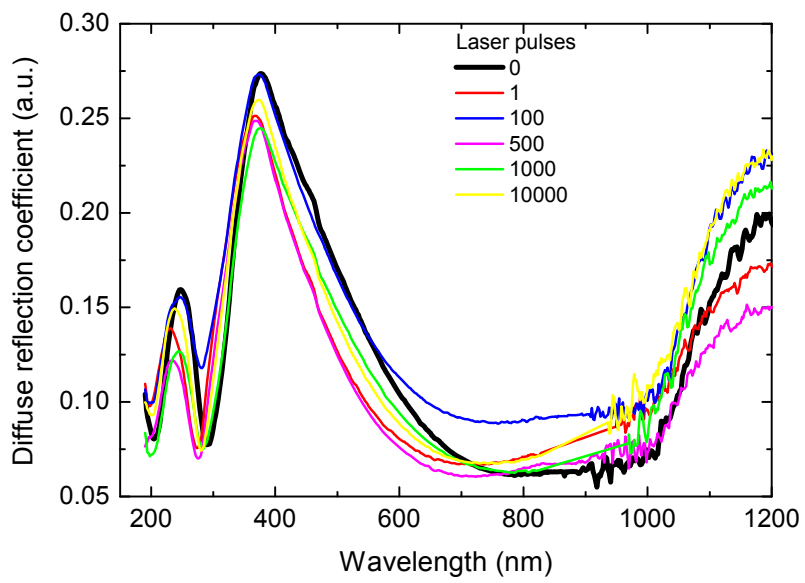

Fig. 8 Diffuse reflection spectra of untreated and laser treated poly-Si solar cells. The numbers of laser shots used for irradiation per spot are shown. Laser process parameters: pulse duration $10 \mathrm{~ns}, 10 \mathrm{kHz}$, pulse energy $0.15 \mu \mathrm{J}$, 6-beam interference, $5 \mu \mathrm{m}$ period, 12 scanned lines between contact grid, distance between lines $100 \mu \mathrm{m}$.

These changes in reflectivity were dependent on the number of laser pulses used to expose a single area with maximal effect at about 100 laser pulses (Fig. 9).

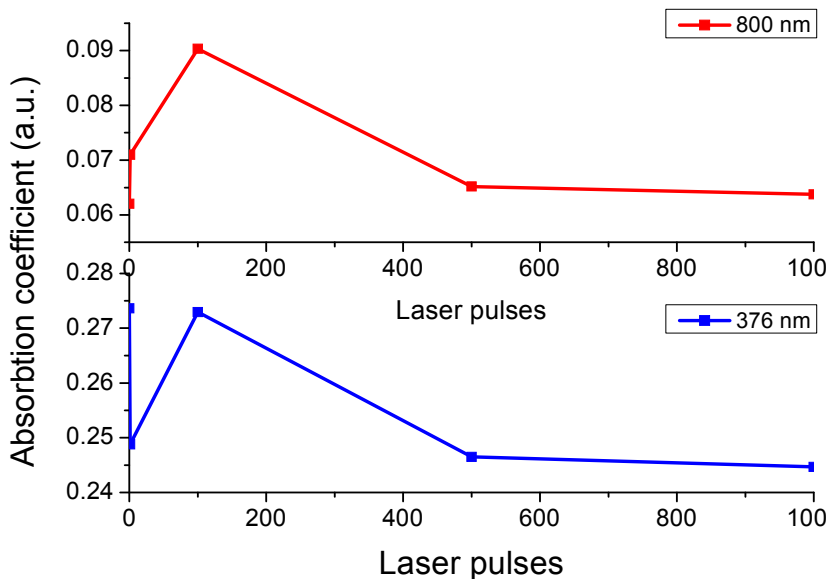

Fig. 9 Variation in absorption at $800 \mathrm{~nm}$ and $375 \mathrm{~nm}$ wavelength depending on the number of laser pulses from the result of Fig. 8 .

Raman spectroscopy is a non-destructive method for the qualitative and quantitative investigation of crystallinity of silicon in solar cells, thermal and surfaces strains [17-20] Crystalline $\mathrm{Si}$ has characteristic vibration modes which appear in Raman spectra as a line at $300 \mathrm{~cm}^{-1}$, the narrow and intensive line at $520 \mathrm{~cm}^{-1}$ and an overtone at $940 \mathrm{~cm}^{-1}$ [21]. Distortions in the lattice of silicon change bonding strength between atoms and amorphous $\mathrm{Si}$ has a characteristic Raman line at $480 \mathrm{~cm}^{-1}$ [22-24]. The intensity ratio of $520 \mathrm{~cm}^{-1}$ and $480 \mathrm{~cm}^{-1}$ Raman lines $\mathrm{I}_{520} / \mathrm{I}_{480}$ is often used as a measure of degree of silicon crystallinity [25]. A shift of the $520 \mathrm{~cm}^{-1}$ line and its asymmetric broadening was observed with a decrease in crystallinity of silicon due to laser irradiation [26-30]. 
Polycrystalline $\mathrm{Si}$ solar cells covered by $\mathrm{SiN}_{\mathrm{x}}$ were treated by an interference field of three laser beams by variation of pulse energy and pulse number. Fig. 10 presents alterations in the Raman spectra, when the number of pulses per spot was increased from 10 to 65000 .

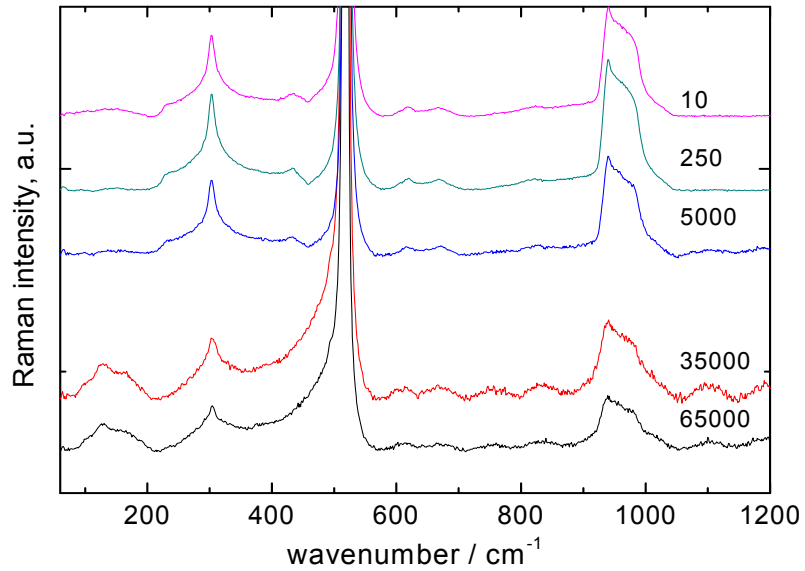

Fig. 10 Raman spectra of the laser-textured poly-Si solar cell with a thin $\mathrm{SiN}_{\mathrm{x}}$ layer, irradiated by nanosecond laser with different numbers of laser pulses. Irradiation technique: 3-beam ns-LBIA @ 10-65000 pulses. Pulse energy $247 \mu \mathrm{J}$.

The line at $520 \mathrm{~cm}^{-1}$ was broadened and its contour became asymmetric. The Raman line shifted to the lowenergy side when a larger number of laser pulses was applied (Fig. 11). An appearance and increase in intensity of the $480 \mathrm{~cm}^{-1}$ line evidenced in an amorphous silicon formation due to laser irradiation by a high number of laser pulses. This indicates on structural modifications in the base material of solar cell - crystalline silicon.

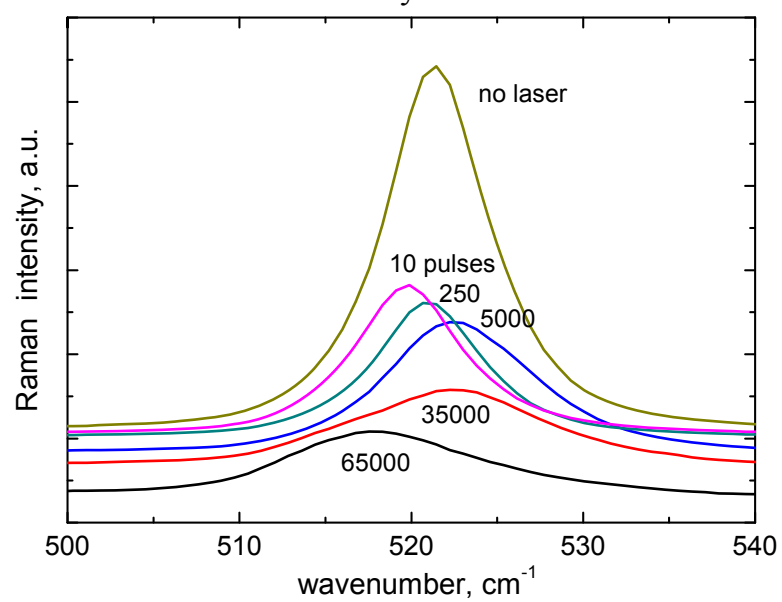

Fig. 11 Fine structure of Raman line at $520 \mathrm{~cm}^{-1}$ of the lasertextured poly-Si solar cell with a thin $\mathrm{SiN}_{\mathrm{x}}$ layer irradiated by nanosecond laser with different number of laser pulses. Irradiation technique: 3-beam ns-LBIA@1065000 pulses. Pulse energy $247 \mu \mathrm{J}$.

The position of the $520 \mathrm{~cm}^{-1}$ line changed regularly depending on the number of laser pulses per spot used for texturing when pulse energy was varied in the range of $0.274-0.312 \mathrm{~mJ}$. No changes in the line position were observed for pulse energy below $0.25 \mathrm{~mJ}$

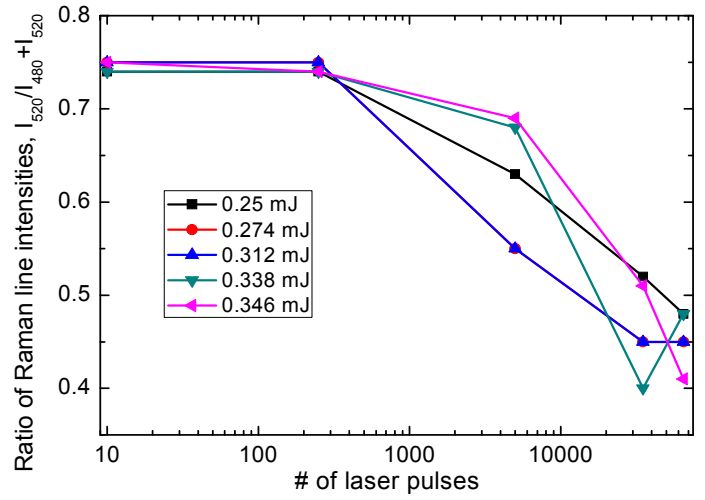

Fig. 12 Ratio of integral intensities of Raman lines $\mathrm{I}_{520} /\left(\mathrm{I}_{480}+\mathrm{I}_{520}\right)$ versus the number of laser pulses.

When a low number of pulses $(<250)$ was applied, crystalline structure of Si was preserved (Fig. 12).

In general, such texturing with nanosecond lasers led to an increase of the absorption in a broad spectral range, but according to photo-electrical characterization, the $\mathrm{p}-\mathrm{n}$ junction was destroyed. However, the method can be useful for texturing Si substrates before doping.

\section{Texturing of poly-Si solar cells using ps-LBIA}

Picosecond lasers with shorter pulse duration produce less thermal defects during laser ablation. This section presents results of laser texturing by ps-LBIA with a high-pulseenergy laser and 4-beam interference (period $2.5 \mu \mathrm{m}$ ).
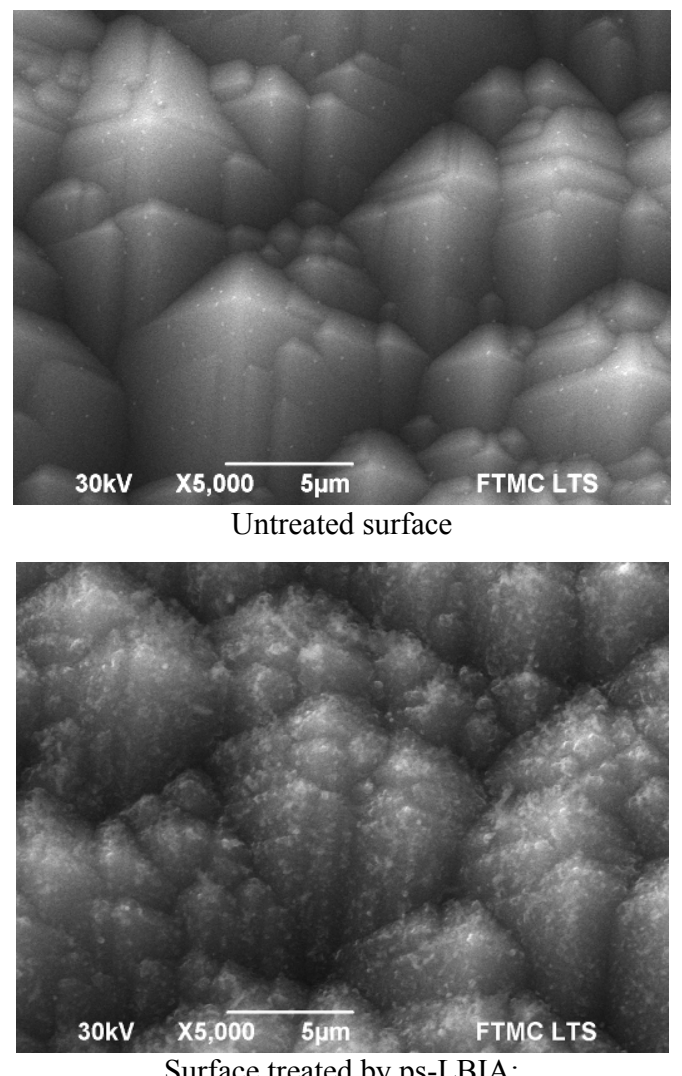

Fig. 13 SEM images of poly-Si solar cell surface untreated and treated by ps-LBIA (Laser \& process: 60 ps, $375 \mu \mathrm{J} @ 4$ kHz, 532 nm, 500 pulses, 4-beam interference, period $2.5 \mu \mathrm{m}$ ). 
The whole surface of a cell was structured; 3 lines were scanned between all contact grids. The distance between the scanning lines was $575 \mu \mathrm{m}$. Fig. 13 shows SEM images of a laser-untreated poly-Si solar cell and after a "gentle" treatment when surface modification appeared only in the $\mathrm{SiN}_{\mathrm{x}}$ layer. No changes appeared in the "native" chemically etched texture of the silicon cell itself, but small white dots indicate modifications in the anti-reflecting layer of $\mathrm{SiN}_{\mathrm{x}}$.

Additional features on the cell surfaces with the size comparable with the wavelength of visible light should affect the light propagation in close vicinity to the cell surface. Therefore, diffuse reflection of the poly-Si solar cells textured by ps-LBIA using a different number of laser pulses per exposure area was examined. Spectra of the cells, laser textured by an interference field of 4 beams with a period of $2.5 \mu \mathrm{m}$ and a common pulse energy of $375 \mu \mathrm{J}$ are presented in Fig. 14. The irradiation per spot was varied from 1 to 2500 laser pulses.

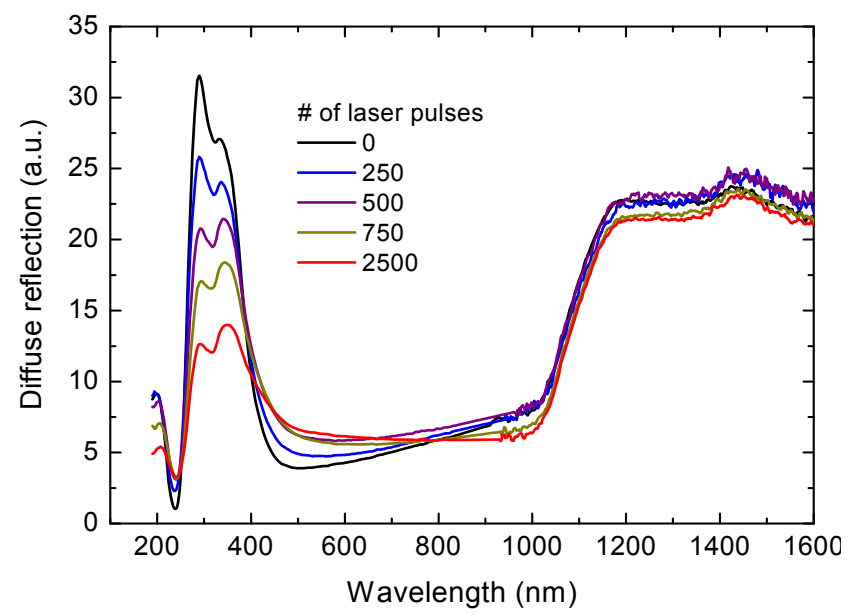

Fig. 14 Diffuse reflection spectra modification after laser texturing. Laser \& process: 532 nm, 60 ps, $375 \mu \mathrm{J} @ 4$ kHz, 4 beam interference, $2.5 \mu \mathrm{m}$ period. The whole surface of a cell was structured by 3 lines scanned between contact grids, distance between lines $575 \mu \mathrm{m}$.

The reduction of diffuse reflection was most prominent in the UV spectral part $(<400 \mathrm{~nm})$ while it increased in the range from 400 to $750 \mathrm{~nm}$.

The specular reflection of textured structures at different angles of light incidence was studied in the spectral range from 400 to $1200 \mathrm{~nm}$ by using an ellipsometric setup. The laser textured samples show a much lower reflectivity in the UV than in the IR range. At long wavelengths the specular reflection increases at angles of incidence exceeding $60^{\circ}$.

The absorption coefficient was evaluated from the ellipsometric measurement data. The most significant modifications in the absorption spectra of the cells were found in the spectral range of 400-1100 nm (Fig. 15). Changes appeared to be not monotonic dependent on the laser irradiation dose (the number of laser pulses per area). The large number of pulses (more than 10) reduced the absorption by up to $35 \%$ probably due to melting of the silicon surface. When the surface of the cell was irradiated by only a few laser pulses per area, an increase in absorption by up to $9.5 \%$ was observed close to the $500 \mathrm{~nm}$ wavelength. Such a "gentle" texturing of the cell surface has a positive effect on coupling of solar light within a solar cell.
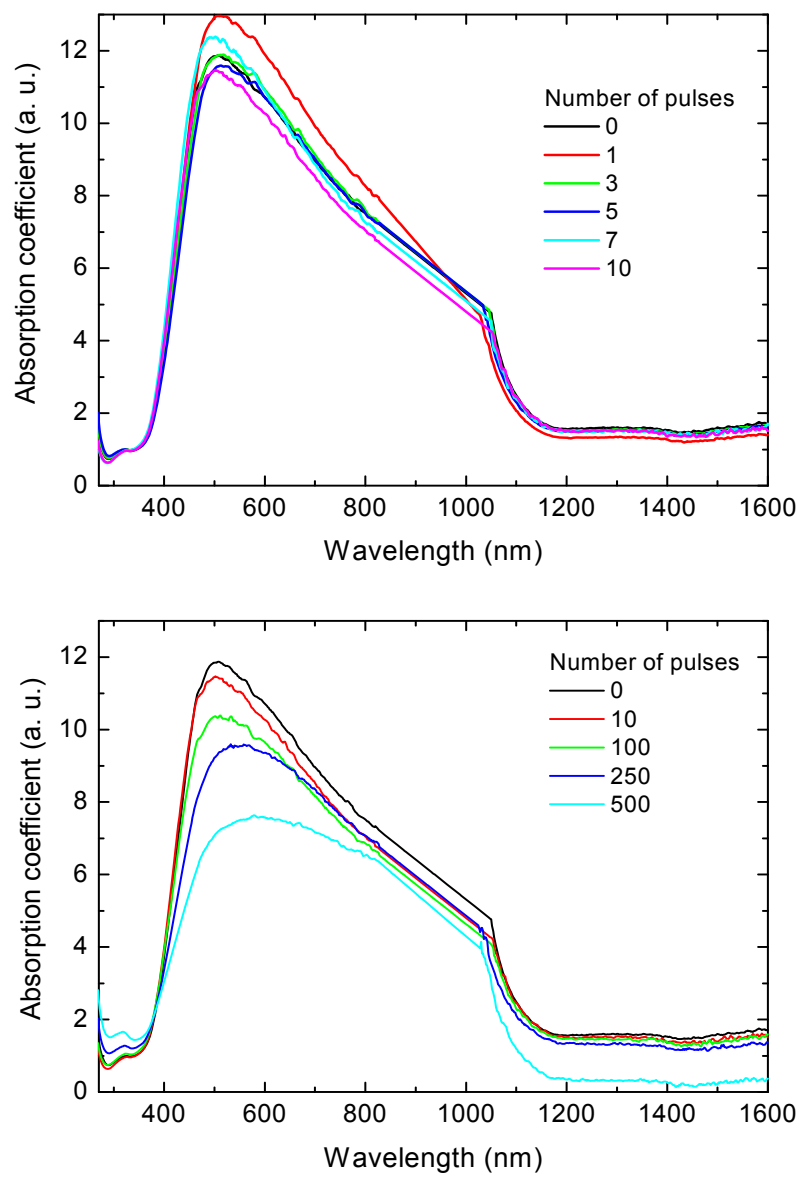

Fig. 15 Absorption spectra modification after laser texturing. Laser \& process: $532 \mathrm{~nm}, 60$ ps, $375 \mu \mathrm{J} @ 4 \mathrm{kHz}, 4$ beam interference, $2.5 \mu \mathrm{m}$ period. Whole surface of a cell was structured; 3 lines scanned between contact grids, distance between lines $575 \mu \mathrm{m}$.

As the modification in absorption was maximal at the wavelength of $500 \mathrm{~nm}$, more detailed research was performed on the influence of the irradiation dose (pulse number) to the absorption of the cell. Fig. 16. presents the results.

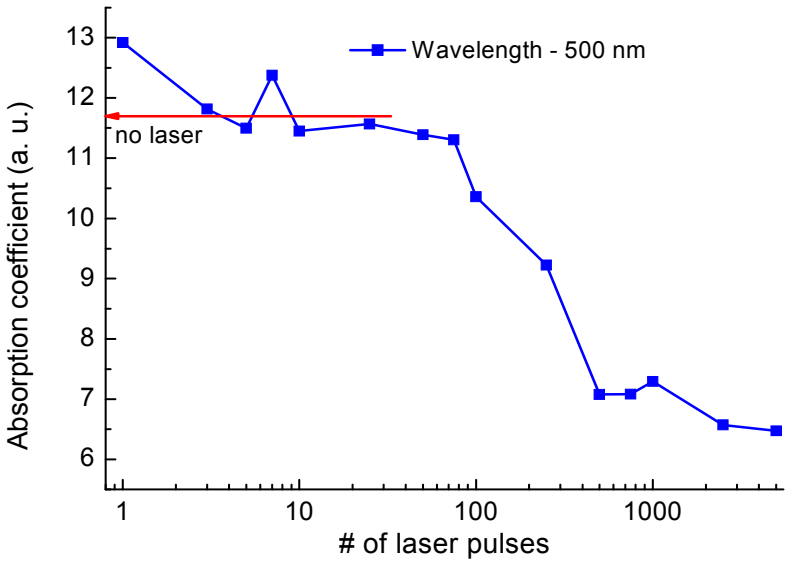

Fig. 16 Modification of the absorption coefficient at the $500 \mathrm{~nm}$ wavelength depending on laser texturing conditions. Atlantic HE laser: 532 nm, 60 ps, $375 \mu \mathrm{J} @ 4$ kHz, 4 
beam interference, $2.5 \mu \mathrm{m}$ period. The whole surface of a cell was structured.

No or a positive laser texturing effect was when the irradiation dose did not exceed 75 pulses per interference area (@375 $\mu \mathrm{J}$ and a spot diameter of $500 \mu \mathrm{m}$ ). Rapid reduction in absorption took place after irradiation by 75 to 500 laser pulses per area and remained stable at a low level with further increase of the pulse number. This change in absorption characteristics reflects the modification in the silicon substrate. This was confirmed by photo-electrical investigations of the laser textured cells.

The volt-ampere characteristics of poly-Si solar cells textured by lasers were measured using a solar imitator and are presented in Fig. 17. For comparison, photovoltaic characteristic of a solar cell non-treated by a laser is presented also in black.

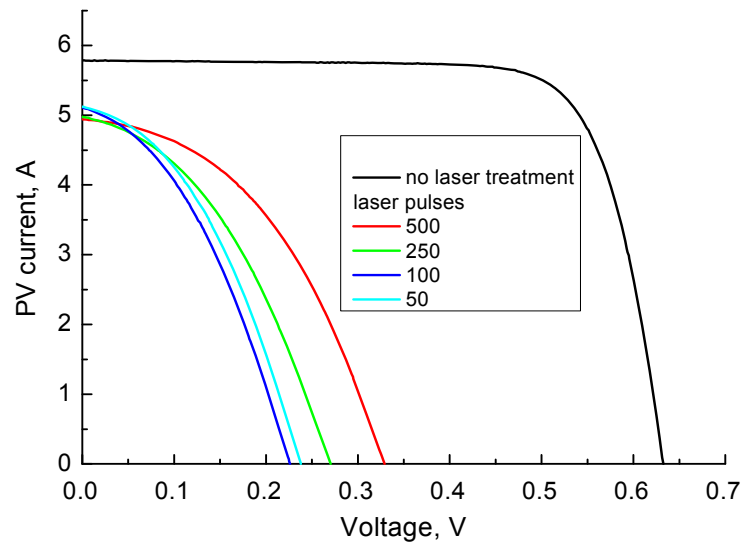

Fig. 17 Volt-ampere characteristics of poly-Si solar cell after laser texturing.

The changes in photo-electrical characteristics exhibit shunt formation during laser texturing of a complete poly$\mathrm{Si}$ solar cell. The shunts could be due to current leakage through a damaged passivation layer.

In order to minimize negative influence of laser texturing to photovoltaic characteristics, a reduced laser pulse energy should be used in texturing, reducing the thickness of the defective layer. It is known, that defective layer was as deep as $80 \mu \mathrm{m}$ when polycrystalline silicon was textured by Nd:YAG laser pulses with an energy of $3.3 \mathrm{~mJ}$ focused into a spot of $20 \mu \mathrm{m}$ [31].

\section{Texturing of Si substrates by fs-LBIA}

As the surface texturing of complete solar cells by lasers is a rather difficult task with hardly predictable results, a part of experiments are dedicated to the texturing of silicon substrates and metallic film on silicon using LBIA technique with a high-pulse-energy femtosecond laser. Textured substrates are intended to be used in solar cell formation by doping and $\mathrm{p}-\mathrm{n}$ junction formation.

6-beam interference and a high pulse energy (up to $6 \mathrm{~mJ}$ ) at a pulse duration of $150 \mathrm{fs}$ were applied to a crystalline Si wafer of a thickness of $0.35 \mathrm{~mm}$. The optical setup was arranged for a $2.5 \mu \mathrm{m}$ period. The modification area per exposure varied depending on the laser pulse energy and the number of pulses applied (Fig. 18). The ablation process intensified with the irradiation dose and thea shape of the holes in the substrate increased providing narrow walls between them.

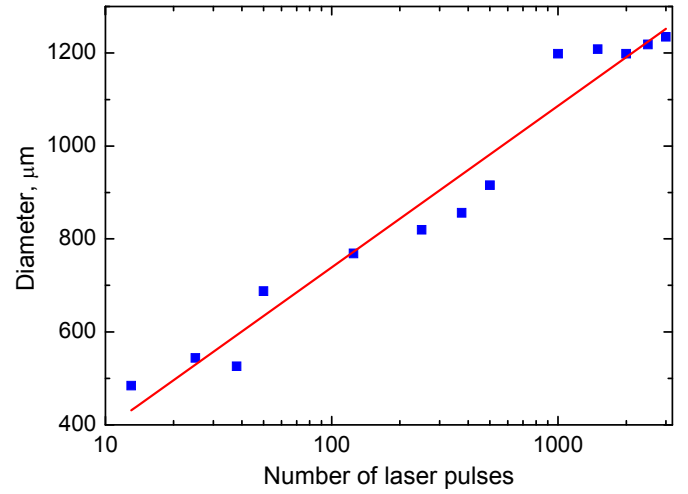

Fig. 18 Diameter of an area laser structured by a single-position exposure, depending on the pulse number. Pulse energy $2.4 \mathrm{~mJ}$.

Small holes were growing into deep valleys with an increasing exposure (pulse number multiplied by pulse energy). Narrow hills remained in places where minima in the interference field distribution existed. At a certain exposure dose, ripples with a period of $250 \mathrm{~nm}$ are formed on the bottom of the holes.

In order to get a uniform texturing whole surface of the Si substrate, a rectangular mask was used to cut the interference field, and a stepper-wise patterning was extended over the whole substrate surface. Stitching of the exposure areas did not have any remarkable effect on the properties of textured surfaces (Fig. 19).

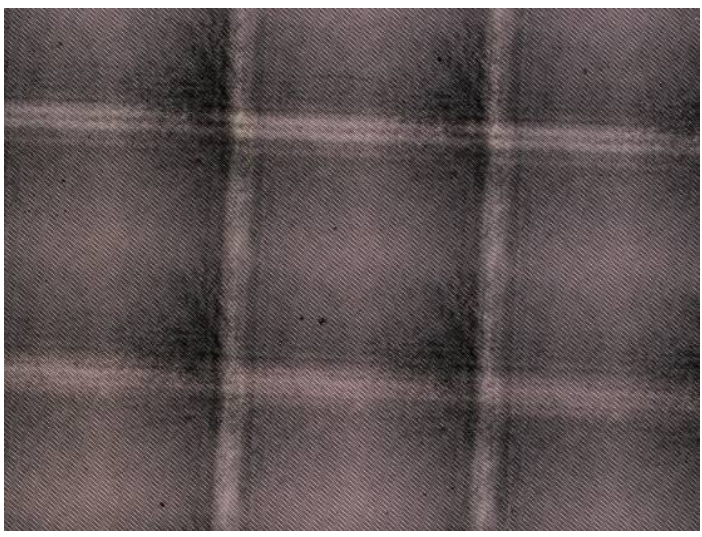

Fig. 19 Optical image of laser textured Si surface, when the laser spot was partially blocked with a rectangular mask and shifted by the mask size.

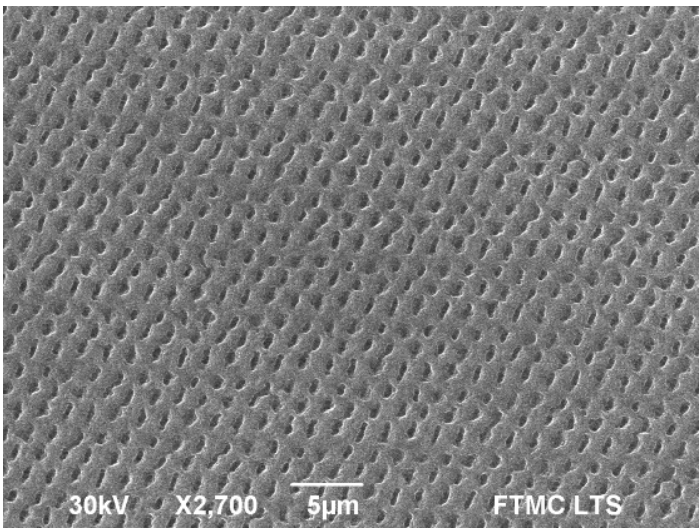


Fig. 20 SEM image of silicon substrate textured by fs-LBIA. 6beam interference, pulse energy $2.4 \mathrm{~mJ}$.

In order to control the period of texturing by interfering laser beams, the experiments were extended by additional precise positioning of the samples without any optical adjustment. A sub-period shift of the workpiece relative to the interference field distribution in different directions (Fig. 21) was applied. A step for a shift was a fraction of the period.

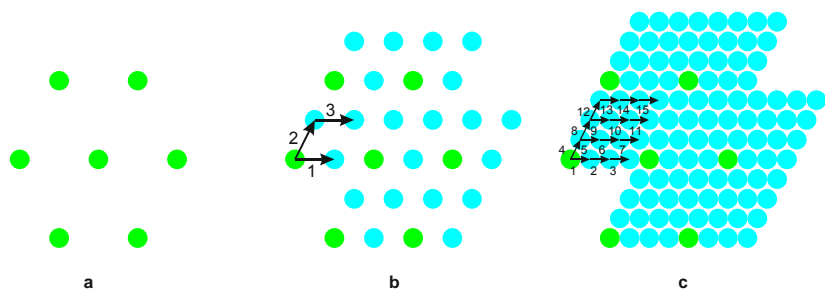

Fig. 21 Method of the laser patterning period modification.

Fig. 22 presents the results of structuring with a reduced period by sub-period shift of the workpiece. The step of movement and the number of laser pulses per position were varied, keeping the pulse energy constant $(2.4 \mathrm{~mJ})$. Structures with a reduced period 2-3 times smaller than the period of interference can be produced in the whole range of the used process parameters. Reduction of the period by 4-5 times leads to asymmetric and defected structure.

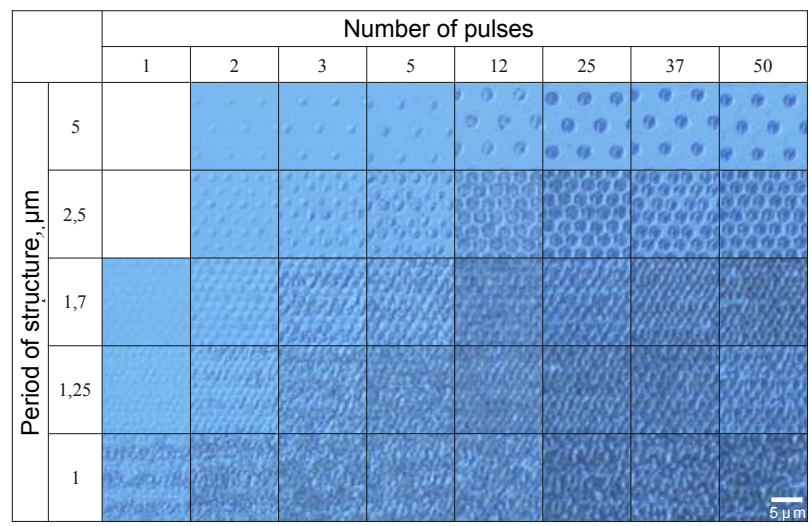

Fig. 22 Optical images of Si surface irradiated by a 6-beam interference field with the period of $5 \mu \mathrm{m}$, depending on pulse number and sub-period shift between exposures. Pulse energy $-2.4 \mathrm{~mJ}$.

\section{Conclusions}

The influence of laser texturing on the structure and optical properties of solar cells has been investigated.

After laser texturing of polycrystalline silicon solar cells, the reflection from their surface was reduced by up to $14 \%$. However, at the same time, the efficiency of the devices was reduced due to a quite deeply defected layer. Structural defects induced by laser irradiation and ablation decreased the lifetime of photo-generated charge carriers, and they could not reach the $\mathrm{p}-\mathrm{n}$ junction. This caused a reduction of the photo-voltaic efficiency.
Investigations on Raman scattering confirmed the changes in the crystalline structure of silicon when highenergy laser pulses were applied.

For laser texturing of silicon substrate it is possible to use direct ablation by interfering laser beams. Reduction in the structure period was demonstrated by up to 3 times by a sub-period shift of the workpiece between exposures. The laser textured substrates can be used for the formation of solar cells.

\section{Acknowledgments}

This research was funded by the grant No. ATE-11/2012 from the Research Council of Lithuania.

\section{References}

[1] K.R. Catchpole, A. Polman, Opt. Express, 16 (2008) 21793.

[2] Y. Wang, T. Sun, T. Paudel, Y. Zhang, Z. Ren and K. Kempa, Nanolett., 12 (2012) 440.

[3] E. Fornies, C. Zaldo and J.M. Albella, Solar Energy Materials and Solar Cells. 87 (2005) 583.

[4] P. Panek, M. Lipinski and J.Dutkiewicz, J. Materials Science 40 (2005) 1459.

[5] E. S. Marstein, H. J. Solheim, D. N. Wright and A. Holt, The 31st IEEE Photovoltaic Specialists Conference, Florida, 2005, 1309.

[6] C. Gerhards, C. Marckman, R. Tolle, M. Spiegel, P. Fath and G. Willeke, The 26th IEEE Photovoltaic Specialist Conference, Anaheim, 1997, 43.

[7] W. A. Nositschka, C. Beneking, O. Voigt and H. Kurz, Solar Energy materials and Solar Cells 76 (2003) 151.

[8] K. Van Nieuwenhuysen, M. Récaman Payo, I. KuzmaFilipek, J. Van Hoeymissen, G. Beaucarne and J. Poortmans, Thin Solid Films. 518 (2010) S80.

[9] B. G. Lee, H. M. Branz, Yu-T. Lin, E. Mazur and M-J. Sher, IEEE Photovoltaic Specialists conference, Austin, Texas, June 3-8, 2012.

[10]E. Yablonovitch and G. D. Cody, IEEE Transactions on Electron Devices. 29 (1982) 300.

[11] N.Wang, Y.Zhu, W.Wei, J.Chen, P.Li and Y.Wen, Opt. Comm., 284 (2011) 4773.

[12] L.Mueller-Meskamp, Y.H.Kim, T.Roch, S.Hofmann, R.Scholz, S.Eckhardt, K.Leo and A.F.Lasagni, Adv. Materials, 24 (2012) 906.

[13] S. Indrišiūnas, B. Voisiat and G. Račiukaitis, Physics Procedia, 41 (2013) 720.

[14] S. Indrišiūnas, B. Voisiat, M. Gedvilas and G. Račiukaitis, J Micromech. Microengineering, 23 (2013) 095034.

[15]B. Voisiat, M. Gedvilas, S. Indrišiūnas and G. Račiukaitis, J. Laser Micro/Nanoengineering, 6 (2011) 185.

[16]L. Yang, B. Kruse, and S.J. Miklavcic, J. Opt. Soc. Am. A. 21 (2004) 1942.

[17]C. Niikura, R. Brenot, J. Guillet, J.E. Bouree, J.P. Kleider, R. Bruggemann and C. Longeaud, Solar Energy Materials \& Solar Cells, 66 (2001) 421.

[18] M.Ivanda, H. Gebavi, D. Ristic, K. Furic, S. Music, M. Ristic, S. Zonja, P. Biljanovic, O. Gamilin, M. Balarin, 
M. Montagna, M. Perrari and G.C. Righini, J. Molecular Structure, 834-836 (2007) 461.

[19] Y. Kang, Y. Qiu, Z. Lei and M. Hu, Optics Lasers Engineering, 43 (2005) 847.

[20] S.Gibilisco, G. Faraci, A.R. Pennisi and A. Irrera, J. Non-Crystalline Solids, 356 (2010) 1948.

[21]A. Kshirsagar, P. Nyaupane, D. Bodas, S.P. Duttagupta and S.A. Gangal, Appl. Surf. Sci, 257 (2011) 5052.

[22] V.A. Volodin, T.T. Kochargina, J.Koch and B.N. Chichkov, Physica. E42 (2010) 1820.

[23] Y. Wang, R. Yue, H. Han, X. Liao, Y. Wang, H. Diao and G. Kong, Materials Letters, 47 (2001) 50.

[24] R.L.C. Vink, G.T. Barkema and W.F. Weg, Phys.Rev. B 63 (2001) 115210.

[25] J. Sancho-Parramon, D. Gracin, M. Modreanu and A. Gajovic, Solar Energy Materials\&Solar Cells. 93 (2009) 1768.
[26] H.S. Mavi, B.G. Rasheed, R.K. Soni, S.C. Abbi and K.P. Jain, Thin Solid Films, 397 (2001) 125.

[27]F.M. Liu, B. Ren, J.H. Wu, J.W. Yan, X.F. Xue, B.W. Mao and Z.Q. Tian, Chem. Phys. Letters, 382 (2003) 502 .

[28] A.G. Abramof, N.G. Ferreira, A.F. Beloto and A.I. Ueta, J. Non-Crystalline Solids, 338-340 (2004) 139.

[29] W. Ke, X. Feng and Y. Huang, J. Appl. Phys, 109 (2011) 083526.

[30] M.N. Islam, A. Pradhan and S. Kumar, J.Appl. Phys, 98 (2005) 024309.

[31]A.D. Dobrzanska-Danikiewic and A. Drygala, Archives of Materials Science and Engineering, 50 (2011) 5 .

(Received: September 12, 2013, Accepted: November 25, 2013) 